ARTICLE

\title{
An integrative treatment model for patients with sexual dysfunctions
}

\author{
P Ramlachan, ${ }^{1} \mathrm{MB}$ ChB, MHlthSc, FECSM; M M Campbell, ${ }^{2} \mathrm{PhD}$ \\ ${ }^{1}$ Newkwa Medical Centre, Durban, South Africa \\ ${ }^{2}$ Department of Psychiatry and Mental Health, Faculty of Health Sciences, University of Cape Town, South Africa
}

Corresponding author: P Ramlachan (drprithy@newkwa.co.za)

Sexuality is recognised as a fundamental and natural need, regardless of age or physical state. Sexual dysfunctions (SDs) are prevalent in the general population and can have a major impact on quality of life and psychosocial and emotional well-being. A high standard of sexual health is regarded as a fundamental right. However, these are self-reported conditions and patients may be reluctant to seek medical help because they are embarrassed. Surveys suggest that men appear to believe that the doctor should initiate questions about sexual health. In addition, SDs such as erectile dysfunction may be markers for comorbid conditions. Hence, a multidisciplinary approach to SDs is required.

S Afr Med J 2014;104(6):445. DOI:10.7196/SAMJ.8374

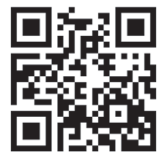

Sexuality has been defined as the way people experience themselves and each other as sexual beings. ${ }^{[1]}$ It encompasses sexual activity, sexual orientation, gender identity and roles, eroticism, pleasure, intimacy, and reproduction. Sexuality is now recognised as a fundamental and natural need regardless of an individual's age or physical state, ${ }^{[2]}$ and is considered an important aspect of holistic healthcare. ${ }^{[3]}$ Sexual dysfunctions (SDs) are prevalent in the general population and can have a major impact on quality of life and psychosocial and emotional well-being. ${ }^{[4]}$ Access to the highest attainable standard of sexual health, including access to sexual and reproductive healthcare services, is a fundamental sexual right. ${ }^{[5]}$

However, SDs are self-reported conditions that require patients to seek medical assistance. Patients may be reluctant to approach their family practitioner for a number of reasons, including embarrassment or shame. A global survey suggests that $60 \%$ of men believe that their doctor should initiate enquiries about sexual health. ${ }^{[6]}$ Patients who present with an SD provide the family practitioner with an ideal opportunity to assess their overall health and to begin the journey of enquiring about their sexual health, as SDs present with a range of comorbid physical and psychological conditions. For example, erectile dysfunction (ED) and cardiovascular disease (CVD) share major risk factors, including age, inactivity, smoking, obesity, dyslipidaemia, depression, hypertension and diabetes mellitus. ${ }^{[7]} \mathrm{ED}$ has been shown to be a sentinel risk factor for CVD. ${ }^{[8]}$

Consequently, SDs such as ED provide the family practitioner with an ideal opportunity to screen men for concomitant comorbidities. A South African survey showed that only $10 \%$ of doctors discuss sex with their patients. ${ }^{[6]} \mathrm{A}$ multidisciplinary and integrative approach to SDs is a new global aim and organisations and researchers working in the field appear committed to furthering its implementation. ${ }^{[9]}$ While this article draws on examples of male SDs, the same algorithm would apply to female patients.

\section{The ICSM-5 diagnostic and treatment algorithm}

The International Consultation of Sexual Medicine-5 (ICSM-5) stepwise diagnostic and treatment algorithm leads family practitioners through a stepwise progression in the assessment of SDs (Fig. 1). ${ }^{[10]}$ The algorithm comprises five steps that may assist practitioners through (i) basic evaluation and history taking; (ii) consideration of the need for specialist care; (iii) patient sexual education; (iv) treatment options; and $(v)$ follow-up evaluation of the patient's sexual well-being following treatment.

\section{Step 1: Basic evaluation}

Step 1 includes the initial evaluation, which covers the patient's sexual, medical and psychosocial history, as well as a focused physical examination and laboratory testing. ${ }^{[10]}$ Because of misinformation and lack of awareness about sexuality and reproduction, male patients may present with concerns or questions about penis size, refractory period after ejaculation, early-morning erections, penile curvature and sexual myths. ${ }^{[1]}$ Distinguishing between sexual concerns, SDs and sexual disorders is essential in the initial evaluation.

\section{Sexual history}

In obtaining the patient's sexual history it is important for practitioners to be sensitive to the social, personal and cultural issues that influence individuals' sexual practices. A structured interviewing process should include enquiry about the patient's (i) sexual activity; (ii) sexual orientation; (iii) sexual practices; (iv) sexual experiences (including development, body image and trauma); $(v)$ sexual cycle; (vi) fertility needs; and (vii) symptoms, duration and severity of the SD. ${ }^{[12]}$ A non-judgemental, empathic and positive attitude may assist the patient in sharing this very personal and sensitive information.

\section{Medical history}

The medical history should allow the family practitioner to establish whether the SD is a stand-alone medical condition or a symptom of another disease. ${ }^{[10]}$ It should also indicate aetiology, addressing the extent to which there are medical, psychiatric, and mixed aetiologies. The coexistence of medical and psychological factors may be important in couples or individuals with chronic SDs. ${ }^{[13]}$

Enquiring about a medical history of the following will assist in determining aetiology: (i) medical conditions such as CVD, diabetes (including thyroid disease), hypogonadism, lower urinary 


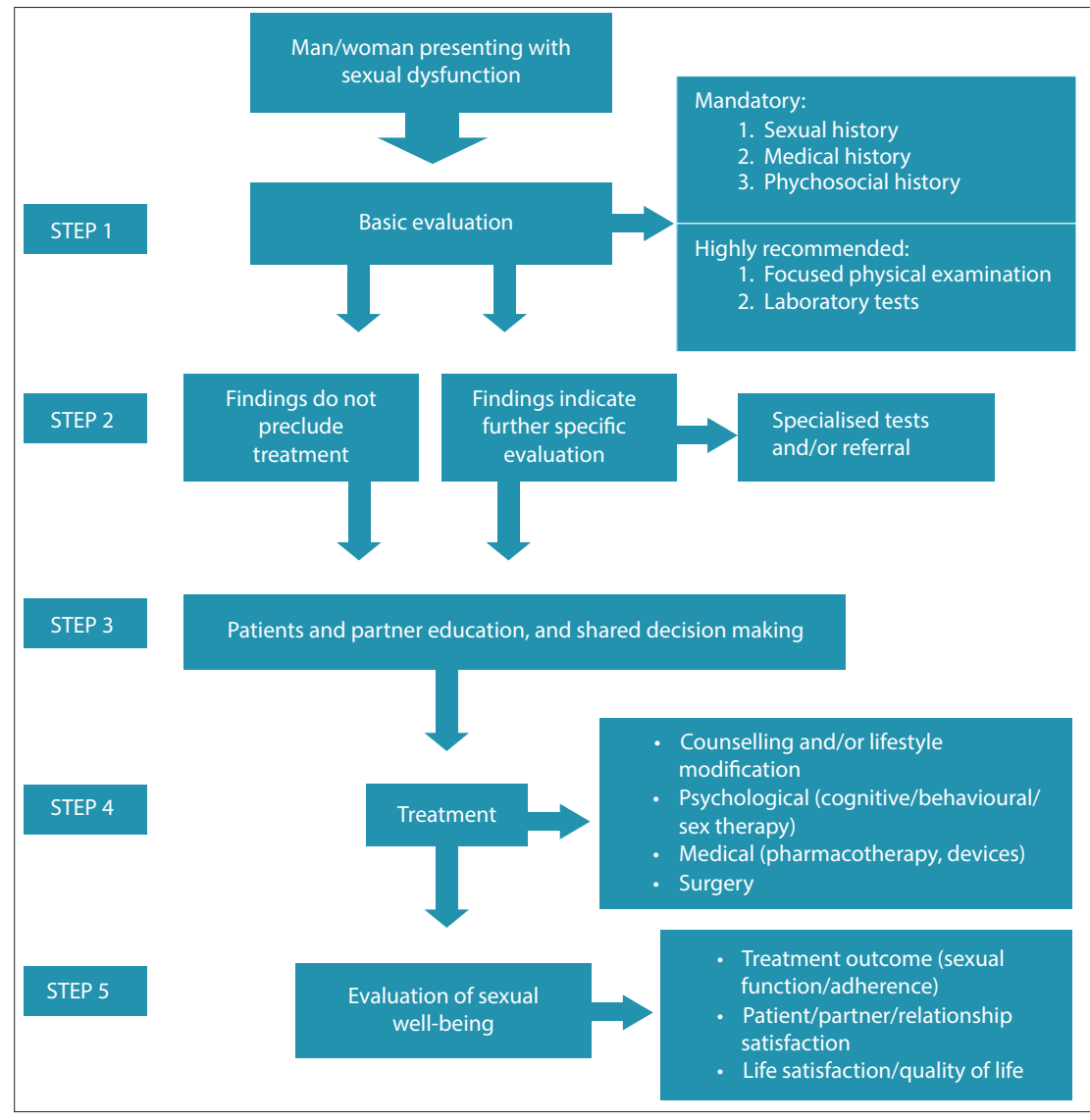

Fig. 1. The International Consultation of Sexual Medicine-5 (ICSM-5) diagnostic and treatment algorithm (for men and women).

tract symptoms, kidney disease, neurological disease, cancer, etc.; (ii) lifestyle factors such as smoking, alcohol use and unhealthy eating habits; (iii) psychological factors such as trauma, emotional problems and psychiatric conditions; and (iv) concomitant medication use. ${ }^{[10]}$

\section{Psychosocial history}

The psychosocial history should elicit the patient's personal understanding of sexuality and sexual practices. ${ }^{[10]}$ This understanding could be influenced by initial sexual experiences, parents' attitudes towards sex and sexuality, religious and spiritual beliefs, etc. Furthermore, the family practitioner should establish how the SD is affecting the patient's relationship with their partner, and the partner's attitudes about sex, the SD and its treatment. ${ }^{[14]}$

Screening tools such as the Brief Sexual Symptom Checklist for Men (BSSC-M) and the Sexual Complaints Screener for Men (SCS-M) are helpful additional tools in eliciting patient information, but should never be a substitute for a thorough sexual, medical and psychosocial history. ${ }^{[15]}$

\section{Laboratory tests}

The choice of investigations depends on the individual circumstances of the patient. $\mathrm{ED}$, for example, is an independent marker for cardiovascular risk and can be the presenting feature of diabetes, so serum lipids and fasting plasma glucose should be measured in all patients. ${ }^{[15]}$ Hypogonadism is a treatable cause of ED that may also make men less responsive, or even nonresponsive, to phosphodiesterase type 5 (PDE5) inhibitors. ${ }^{[16]}$ Therefore, all men with ED should have serum testosterone measured in a blood sample taken in the morning between $08 \mathrm{~h} 00$ and $11 \mathrm{~h} 00 .{ }^{[15]}$ Additional tests will depend on the physical examination and history.

\section{Step 2: Need for specialised treatment}

The ICSM-5 stepwise diagnostic and treatment algorithm includes consideration of the basic evaluation findings to determine the need for specialist care. Specialised tests and referrals are usually indicated in lifelong or primary SDs, in the case of specific anatomical or endocrine factors, or in complicated psychiatric or interpersonal problems. ${ }^{[10]}$ Specialised treatment is also indicated following failure of initial therapy. Specialised tests for assessing aetiology include nocturnal penile tumescence and rigidity, dynamic duplex ultrasound, dynamic infusion cavernosometry, cavernosography internal pudendal arteriography and biothesimetry. ${ }^{[17]}$ These investigations are typically used to tailor specific vascular surgery in arterial disease (for cyclists and as a result of trauma), hypogonadism or Peyronie's disease.

\section{Step 3: Patient and partner sexual education}

This step focuses on educating the patient and partner about general sexual function and dysfunction, as well as relationship enhancement techniques. ${ }^{[10]}$ This educational process may assist with improved subjective well-being by equipping the patient with knowledge and techniques to manage sexual health and sexual functioning in a more adaptive manner, improving quality of life and empowering the patient. ${ }^{[18]}$

\section{Step 4: Treatment options}

A number of treatment options are available, depending on the aetiology of the SD. An integrative treatment model emphasises a patient-centred approach towards sexual health that includes counselling and lifestyle modification, psychological therapies (including cognitive behavioural therapy and sex therapy), medical interventions (pharmacology and devices) and surgery. ${ }^{[10]}$

\section{Step 5: Evaluating the patient's} sexual well-being after treatment

After treatment the family practitioner evaluates the patient's sexual well-being in relation to treatment outcomes (current sexual functioning and adherence to treatment), the patient-partner relationship (including interpersonal and sexual satisfaction), and the patient's reported life satisfaction or quality of life. ${ }^{[10]}$

\section{Herbal medicine use in the treatment of male SDs}

Working from an integrative approach, it is important for family practitioners to acknowledge that health is grounded in a broad cultural, spiritual and religious context. ${ }^{[10]}$ Herbal and traditional medicine are part of indigenous African knowledge and healing systems and have a potential role in sexual health. ${ }^{[19]}$ It is important to understand 
why some patients use these traditional medications for the treatment of SDs. Sexual health concerns can be interpreted as the result of natural (disease, psychological stress) or supernatural (displeased ancestral and religious spirits, witchcraft) causes. ${ }^{[20]}$ The World Health Organization (WHO) estimates that $75 \%$ of the African population use traditional medicines. ${ }^{[21]}$ Such herbal remedies have been used to treat impotence, prostate problems and male menopause, while aphrodisiacs have been used to increase libido (sexual desire, arousal and motivation), sexual potency (effectiveness of erection) and sexual pleasure. ${ }^{[19,20]}$ Male patients may turn to medicinal plants because of the relatively low cost of these medicines, the difficulty in obtaining orthodox medication, particularly in rural areas, the understanding that traditional plant medications may be safer than other medications, and because community experiences indicate efficacy.

\section{Conclusion}

In managing patients who present with SDs, family practitioners are encouraged to draw from an integrative model such as the ICSM-5 stepwise diagnostic and treatment algorithm. This tool may assist clinicians in conducting a basic evaluation and history taking, considering the need for specialist care, conducting patient sexual education, talking through and considering available treatment options, and evaluating the patient's sexual well-being following treatment. Furthermore, it is important to consider the broader cultural, spiritual and religious context within which sexual healthcare exists.

\section{Take home messages}

- SD may have a major impact on quality of life and psychosocial and emotional well-being.

- Several chronic diseases, not directly linked to SD, may still have a major impact on sexual health.

- SD may be the key to assessing men's health status.

\section{References}

1. Rathus SA, Nevid JS, Ficher-Rathus L. Essentials of Human Sexuality. Needham Heights, MA: Allyn and Bacon, 1998

2. Pangman VC, Sequire M. Sexuality and the chronically older adult. A social justice issue. Sex Disabil 2000;18:49-59. [http://dx.doi.org/10.1023/A:1005477712133]

3. Royal College of Nursing. RCN Sexual Health Strategy: Guidelines for Nursing Staff. London: RCN 2001.

4. Laumann EO, Paik A, Rosen RC. Sexual dysfunction in the United States: Prevalence and predictors. JAMA 1999;281(6):537-544. [http://dx.doi.org/10.1001/jama.281.6.537]

5. Montorsi F, Adaikan G, Becher E, et al. Summary of the recommendations on sexual dysfunctions in men. J Sex Med 2010;7:3572-3588. [http://dx.doi.org/10.1111/j.1743-6109.2010.02062.x]

6. Laumann EO, Nicolosi A, Glasser DB, et al. Sexual problems among women and men aged $40-80 \mathrm{y}$ : The Global Study of Sexual Attitudes and Behaviours. Int J Impot Res 2005;17:39-57.

7. Jackson G. Prevention of cardiovascular disease by the early detection of erectile dysfunction. Int J . Jackson G. Prevention of cardiovascular disease by the early detection
Impot Res 2008;20(2):S9-S14. [http://dx.doi.org/10.1038/ijir.2008.47]

Impot Res 2008;20(2):S9-S14. [http://dx.doi.org/10.1038/ijir.2008.47]
Guo W, Liao C, Zou Y, et al. Erectile dysfunction and risk of clinical cardiovascular events: A metaGuo W, Liao C, Zou Y, et al. Erectile dysfunction and risk of clinical cardiovascular events: A meta-
analysis of seven cohort studies. J Sex Med 2010;7:2805-2816. [http://dx.doi.org/10.1111/j.17436109.2010.01792.x]

9. Berry MD, Berry PD. Contemporary treatment of sexual dysfunction: Reexamining the biopsychosocial model. J Sex Med 2013;10:2627-2643. [http://dx.doi.org/10.1111/jsm.12273]

10. Hatzichristou D, Rosen RC, Derogatis LR, et al. Recommendations for the clinical evaluation of men and woman with sexual dysfunction. J Sex Med 2010;7:337-348. [http://dx.doi.org/10.1111 /j.1743-6109.2009.01619.]

11. Beckwith AC, Green J, Goldmeier D, Hetherton J. Dysfunctional ideas ('male myths') are a result of, rather than a cause of, psychogenic erectile dysfunction in heterosexual men. Int J STD AIDS 2009;20:638-641. [http://dx.doi.org/10.1258/ijsa.2008.008468]

12. Kingsberg SA. Taking a sexual history. Obstet Gynecol Clin North Am 2006;33:535-547. [http://dx.doi. org/10.1016/j.ogc.2006.09.002]

13. Hengefeld MW. Erectile disorder: A psychosexological review. In: Jonas U, Thon WF, Stief CG, eds. Erectile Dysfunction. Berlin: Springer Verlag, 1991:14-22. [http://dx.doi.org/10.1007/978-3-66200986-4_18]

14. Fisher WA, Eardley I, McCabe M, Sand M. Erectile dysfunction (ED) is a shared concern of couples. I: Couples conceptions of ED. J Sex Med 2009;6:3111-3124. [http://dx.doi.org/10.1111/j.17436109.2009.01432.x]

15. Hatzichristou D, Rosen RC, Broderick G, et al. Clinical evaluation and management strategy for sexual dysfunction in men and woman. J Sex Med 2004;1:49-57. [http://dx.doi.org/10.1111/j.17436109.2004.10108.x]

16. Shabsigh R, Kaufman J, Aurora CO, Steidle C, Padma-Natha H. Testosterone replacement therapy with testosterone gel $1 \%$ converts sildenafil non-responders in men with hypogonadism and erectile dysfunction who failed prior sildenafil therapy. J Urol 2004;172:658-663.

17. Ghanem $\mathrm{H}$, Shamoul R. An evidence based perspective to commonly performed erectile dysfunction investigations. J Sex Med 2008;5:1582-1589. [http://dx.doi.org/10.1111/j.1743-6109.2007.00665.x]

18. Bachmann G. Female sexuality and sexual dysfunction. Are we stuck on the learning curve? J Sex Med 2006;3:639-645. [http://dx.doi.org/10.1111/j.1743-6109.2006.00265.x]

19. Mugisha MK, Origa HO. Traditional herbal remedies used in the management of sexual impotence Mugisha MK, Origa HO. Traditional herbal remedies used in the management of
and erectile dysfunction in western Uganda. Africa Health Sciences 2005;5(1):40-45.

20. Pearson S, Makadzange P. Help seeking behaviour for sexual health concerns: A qualitative study of men in Zimbabwe. Culture, Health and Sexuality 2008;10(4):361-376. [http://dx.doi. org/10.1080/13691050801894819]

21. World Health Organization (WHO). WHO Traditional Medicine Strategy 2002-2005. Geneva: WHO 2002 